\title{
Impact of Commercially Available Diabetic Prescription Diets on Short- Term Postprandial Serum Glucose, Insulin, Triglyceride and Free Fatty Acid Concentrations of Obese Cats
}

\author{
Kana MIMURA ${ }^{1)}$, Akihiro MORI ${ }^{1) *}$, Peter LEE $^{2)}$, Kaori UEDA ${ }^{1)}$, Hitomi ODA ${ }^{1)}$, Kaori SAEKI ${ }^{1)}$, Toshiro ARAI ${ }^{2)}$ and \\ Toshinori $\mathrm{SAKO}^{1)}$ \\ ${ }^{1)}$ Department of Veterinary Nursing and Technology, School of Veterinary Science, Nippon Veterinary and Life Science University, 1-7-1 \\ Kyonancho, Musashino, Tokyo 180-8602, Japan \\ ${ }^{2)}$ Department of Veterinary Medicine, School of Veterinary Science, Nippon Veterinary and Life Science University, 1-7-1 Kyonancho, \\ Musashino, Tokyo 180-8602, Japan
}

(Received 9 July 2012/Accepted 17 February 2013/Published online in J-STAGE 1 March 2013)

\begin{abstract}
Diet therapy is an important treatment component available for obese cats. In this study, the impact of four commercially available prescription diet regimens ( 1 for general use and 3 aimed at treating obesity and diabetes mellitus (DM)) on short-term postprandial serum glucose, insulin, triglyceride and nonesterified fatty acid (NEFA) concentrations was investigated with five obese cats. The diet regimens used were as follows: C/D dry (general use: moderate protein, moderate fat, high carbohydrate and low fiber), M/D dry (DM: high protein, high fat, low carbohydrate and high fiber), W/D dry (DM: high protein, low fat, high carbohydrate and high fiber) and Diabetic dry (DM: high protein, low fat, low carbohydrate and high fiber). A significant reduction (10-13\%) in postprandial glucose (area under the curve; AUC) was observed with the M/D and Diabetic diets, which both contained lower concentrations of carbohydrates than the C/D diet. An accompanying significant reduction (30-36\%) in postprandial insulin AUC was also observed with the three DM diets, which all had higher amounts of fiber, as compared with the C/D diet. Lastly, a significant increase (32-65\%) in postprandial NEFA AUC was observed with the M/D and Diabetic diets as compared with the C/D diet. Therefore, dietary amounts of carbohydrates and fiber, as opposed to protein content or dietary fat, appear to have a very significant impact on postprandial glycemia and subsequent insulin requirement levels in obese cats. In addition, dietary amounts of carbohydrates may also impact lipid metabolism in obese cats. KEY WORDS: carbohydrate, diet, feline, glucose, insulin.
\end{abstract}

doi: 10.1292/jvms.12-0310; J. Vet. Med. Sci. 75(7): 929-937, 2013

A prevalent health care issue among privately owned cats (25-40\%) is being overweight and obese body conditions. The combination of feeding style, neutering and reduced amount of exercise can lead to the development of obesity in these cats and in conjunction with insulin resistance can contribute to the eventual development of Type 2 diabetes mellitus (DM) [6, 12, 21, 24, 25, 31].

Dietary modification is an important measure for treatment and prevention of obesity and DM. Recent studies have indicated that a diet high in carbohydrate and low in protein results in greater postprandial glucose and insulin concentrations as compared with a low carbohydrate and high protein diet in lean cats [8]. In their natural habitat, cats would normally consume prey high in protein, with moderate amounts of fat, and a minimal amount of carbohydrate; thus, cats are metabolically adapted for greater metabolism of proteins and lower utilization of carbohydrates, as compared with other omnivores. In addition, use of an appropriate diet for cats suffering from DM may serve as a treatment

*Correspondence to: Mori, A., Department of Veterinary Nursing and Technology, Nippon Veterinary and Life Science University 1-7-1 Kyonancho, Musashino, Tokyo 180-8602, Japan. e-mail: amori@nvlu.ac.jp

(C)2013 The Japanese Society of Veterinary Science component in managing DM and even ameliorate some of the symptoms. Traditionally, the approach has been to feed a high-fiber, low-fat diet for glycemic control, because it can significantly reduce preprandial and postprandial serum glucose concentrations in feline DM $[18,30]$. However, according to previous studies, low-carbohydrate diets may also aid glycemic control in Type 2 DM by reducing hyperglycemia and aiding in recovery from glucose toxicity $[1,13,27]$. Several studies have employed a test meal, for evaluating postprandial glucose concentrations, insulin concentrations or changes in body weight [4, 19, 20, 37]. However, information on the effects of the use of commercially available prescription diets to manage feline obesity is scarce and thus far includes only two studies that have investigated the effects of these diets on glucose and insulin concentrations in cats $[8,26]$. Furthermore, our previous study demonstrated that commercially available diabetic prescription diets affect postprandial glucose and insulin concentrations in nonobese healthy cats [28]; however, no study has investigated the effects in obese cats.

Up until now, the majority of reports concerning the influence of diet composition on felines has focused predominantly on diabetic felines, as clinically relevant test subjects. However, it is unknown what baseline effect diet composition has in obese felines, especially on postprandial glucose, insulin, triglyceride (TG) and nonesterified fatty acid 


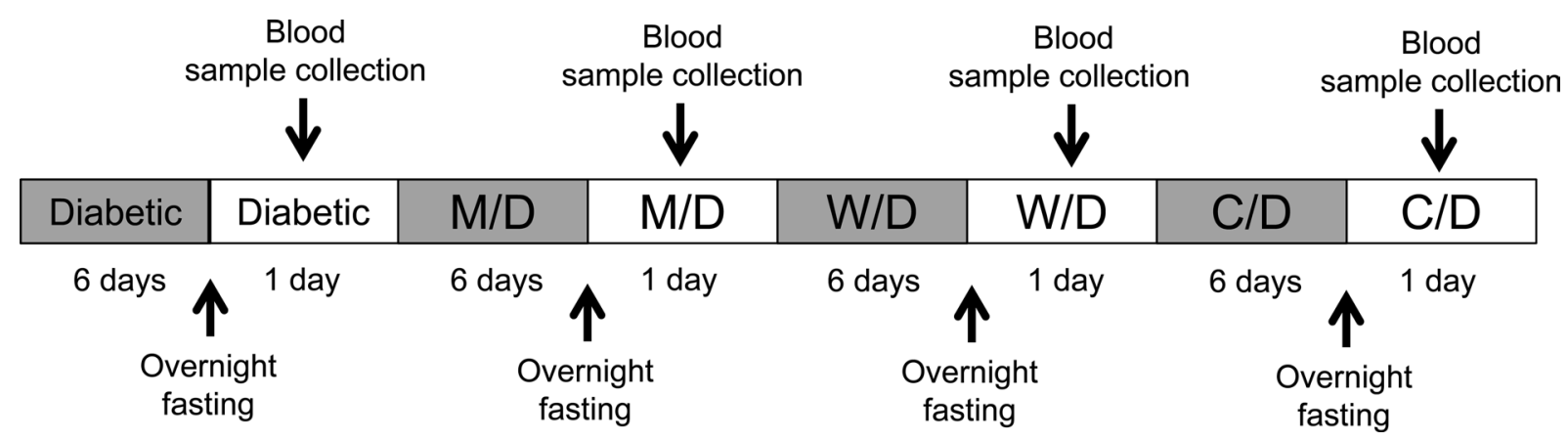

Fig. 1. Feeding protocol for the animals. The cats underwent diet regimen rotation, with each regimen lasting for up to 7 days and no washout period in between regiments. Cats started off with Diabetic dry diet, and this was followed by the M/D dry diet, W/D dry diet and then C/D dry diet. Blood was always collected on the seventh and final day of each diet regimen so as to allow for sufficient time for acclimation to the diet regimen of the animal in order to observe any impact on postprandial glucose, insulin, nonesterfied fatty acid and triglyceride concentrations.

(NEFA) concentrations, four important key parameters often monitored and assessed in obese and diabetic felines. Therefore, the aim of this study was to compare the short-term effects of four different commercially available prescription dry diets on postprandial glucose, insulin, TG and NEFA concentrations in obese felines. The four different diets were as follows: $\mathrm{C} / \mathrm{D}$ dry (moderate protein, moderate fat, high carbohydrate and low fiber), M/D dry (high protein, high fat, low carbohydrate and high fiber), W/D dry (high protein, low fat, high carbohydrate and high fiber) and Diabetic dry (high protein, low fat, low carbohydrate and high fiber).

\section{MATERIALS AND METHODS}

Animals: Five obese (5 castrated males; 4.9-7.4 kg BW; 4-5 BCS; 1-5 years old) adult domestic cats, which were originally obtained from AQS Co., Ltd. (Narita, Japan) and subsequently maintained in our laboratory for research, were used in this study. BCS was determined on a five point scale: 1, thin; 2, lean; 3, optimal; 4, obese; and 5, gross. Obese cats were fed on a C/D dry diet (Hill's Colgate, Tokyo, Japan) twice a day, and caloric intake was set at half of $1.0 \times$ RER $\left(\mathrm{BW}^{0.75} \times 70\right)$ [36], where RER represents a resting energy requirement. Approval for the work was given by the Nippon Veterinary and Life Science University Animal Research Committee.

Animal feeding protocol: In order to determine and compare the short-term effects of 4 different commercially available prescription diets, on postprandial serum glucose, insulin, TG and NEFA levels, the 5 obese cats were fed the same diet for 7 days followed by diet rotation (Fig. 1). On the last day of each interval period, the cats underwent overnight fasting, with each subsequent new diet being supplied at 9:00 am on the subsequent day. The obese cats were allowed to eat for $30 \mathrm{~min}$, and caloric intake was set at half of $1.0 \times \mathrm{RER}\left(\mathrm{BW}^{0.75} \times 70\right)$. We confirmed that over $50 \%$ of all the food was eaten within $30 \mathrm{~min}$ for all 5 obese cats. Afterwards, we checked the amount of residual food at 2-hr intervals until the food was completely finished being eaten.
We also confirmed that there was no significant change in body weight throughout the experimental feeding period (Diabetic dry=6.3 $\pm 1.1 \mathrm{~kg}, \mathrm{M} / \mathrm{D}$ dry= $6.3 \pm 1.1 \mathrm{~kg}, \mathrm{~W} / \mathrm{D}$ dry $=6.3 \pm 1.1 \mathrm{~kg}, \mathrm{C} / \mathrm{D}$ dry=6.3 $\pm 1.2 \mathrm{~kg}$ ).

The prescription diets used and being compared in this study were as follows: C/D Multicare Feline Bladder Health dry diet (moderate protein, moderate fat, high carbohydrate and low fiber; Hill's Colgate), M/D Feline Weight loss-Low Carbohydrate-Diabetic dry diet (high protein, high fat, low carbohydrate and high fiber; Hill's Colgate), W/D Feline Low Fat - Diabetic - Gastrointestinal dry diet (high protein, low fat, high carbohydrate and high fiber; Hill's Colgate), and Feline diabetic dry diet (high protein, low carbohydrate, low fat, high fiber; Royal Canin, Tokyo, Japan). Each diet has a particular aim suggested and recommended by the manufacturer.

For example, the $\mathrm{C} / \mathrm{D}$ dry diet is primarily aimed at nutritional management of felines with struvite-related feline lower urinary tract disease. The diet may also be useful for a variety of other conditions. Thus, it appears to be a general, multiuse diet lacking fiber, but rich in protein, carbohydrates and fat. Alternatively, the M/D diet and diabetic diet are mostly used for weight control and nutritional management of fiber-responsive diseases, such as DM, diarrhea and constipation. These diets target obesity and diabetes and are rich in protein and fiber, but contain significantly reduced levels of carbohydrates. Lastly, the W/D diet is also primarily aimed at weight control and fiber responsive diseases, such as DM, diarrhea and constipation. The W/D diet is very similar in nature to the M/D diet; however, in contrast, it is rich in carbohydrates and low in fat. The chemical composition of each diet is presented in Table 1.

Blood sample collection: Blood samples were collected by bleeding $1 \mathrm{~m} l$ from the jugular vein of the obese cats 30 min prior to and $1,2,3,4,6,8$ and $10 \mathrm{hr}$ postfeeding of the diets. Blood samples were collected into polypropylene tubes and allowed to clot at room temperature for $30 \mathrm{~min}$. Subsequently, they were centrifuged $(1,700 \times g)$ at $4^{\circ} \mathrm{C}$ for $10 \mathrm{~min}$ to separate the serum. After centrifugation, the serum 
Table 1. Chemical compositions of the prescription diets

\begin{tabular}{ccccc}
\hline & $\mathrm{C} / \mathrm{D}$ & $\mathrm{M} / \mathrm{D}$ & W/D & Diabetic \\
\hline Carbohydrates & 10.5 & 3.7 & 10.7 & 6.7 \\
Protein & 8.3 & 12.3 & 11.1 & 12.3 \\
Fat & 4.0 & 5.2 & 2.8 & 3.2 \\
Fiber & 0.2 & 1.3 & 2.2 & 3.1 \\
Calcium & 0.18 & 0.21 & 0.28 & 0.25 \\
Potassium & 0.21 & 0.17 & 0.24 & 0.27 \\
Phosphorus & 0.16 & 0.18 & 0.22 & 0.23 \\
Magnesium & 0.01 & 0.01 & 0.02 & 0.02 \\
Sodium & 0.09 & 0.09 & 0.09 & 0.13 \\
Taurine & 0.06 & 0.07 & 0.06 & 0.07 \\
\hline
\end{tabular}

Values are presented as $\mathrm{g} / 100 \mathrm{kcal}$ of dry food. C/D dry=high carbohydrate, moderate protein, moderate fat and low fiber. M/D dry=low carbohydrate, high protein, high fat and high fiber. W/D dry=high carbohydrate, high protein, low fat and low fiber. Diabetic dry=low carbohydrate, high protein, low fat and high fiber. Dietary energy breakdown: $\mathrm{C} / \mathrm{D}$ dry $=3,885 \mathrm{kcal} / \mathrm{kg}$ ( $383 \mathrm{kcal} /$ cup, one 8 fluid ounce cup=3 ounces $=85.05 \mathrm{~g}$ ), M/D dry=3,960 $\mathrm{kcal} / \mathrm{kg}$ ( $495 \mathrm{kcal} / \mathrm{cup}$, one 8 fluid ounce cup $=4$ ounces $=113.4 \mathrm{~g}), \mathrm{W} / \mathrm{D}$ dry=3,227 kcal $/ \mathrm{kg}(281 \mathrm{kcal} / \mathrm{cup}$, one 8 fluid ounce cup=3 ounces $=85.05 \mathrm{~g}$ ), Diabetic dry=276 kcal/cup, $332.7 \mathrm{kcal} / 100 \mathrm{~g}, 85 \mathrm{~g} /$ cup. Dietary energy breakdown information is available from the Hill's Pet Food and Royal Canin websites:

C/D dry http://www.hillspet.com/products/pd-feline-cd-multicare-feline-bladder-health-dry.html

M/D Dry http://www.hillspet.com/products/pd-md-feline-weight-loss-low-carbohydrate-glucose-managementdry.html

W/D Dry http://www.hillspet.com/products/pd-feline-wd-feline-low-fat-diabetic-gastrointestinal-dry.html Diabetic dry http://www.royalcanin.ca/index.php/Veterinary-Products/Feline-Nutrition/Veterinary-TherapeuticFormulas/Diabetic-Dry

was collected and stored at $-80^{\circ} \mathrm{C}$ until further use.

Serum glucose, immunoreactive insulin, TG and NEFA concentration analysis: Serum NEFA, glucose and TG concentrations were measured by an enzymatic method using an Iatro tech NEFA kit (Mitsubishi Kagaku Iatron, Tokyo, Japan), Iatro LQ GLU kit (Mitsubishi Kagaku Iatron) and Cholestest TG kit (Sekisui Medical Co., Ltd., Tokyo, Japan), respectively and processed by a Hitachi 7180 Clinical Analyzer (Hitachi High-Technologies Corporation, Tokyo, Japan). Serum insulin (immunoreactive insulin) concentration was measured using an ELISA kit (Morinaga Institute of Biological Science, Yokohama, Japan) according to the manufacturer's instructions (the intra-assay CV and interassay CV were $\leq 6 \%$ and $\leq 10 \%$, respectively) [29].

Statistical analysis: Data are presented as the mean \pm SD. Peak concentration and time to peak were also determined. Total area under the curve (AUC) was estimated as the postprandial summary variable and calculated by the trapezoidal rule in units of concentration $\times$ hours. Significance was determined using one-way repeated measures ANOVA and Bonferroni's multiple comparison test for comparison of BW, AUC, peak concentrations and time to peak or twoway repeated measures ANOVA and Bonferroni's multiple comparison test for temporal analysis of glucose, insulin, TG and NEFA concentrations between the four diets, using GraphPad Prism 5 (GraphPad Software, Inc., La Jolla, CA, U.S.A.). The significance level was set at $P<0.05$.

\section{RESULTS}

Food intake: Obese cats used in the present study ate slowly and did not eat all of the provided food at the same pace. Therefore, in order to standardize a baseline amount of food consumed, we determined that our experiment could begin when theses cats consumed $\geq 50 \%$ of all of the provided food within $30 \mathrm{~min}$. With Diabetic dry diet, 1 cat ate all of its food within $30 \mathrm{~min}$, whereas the remaining 4 ate $\geq 50 \%$ of their food within $30 \mathrm{~min}$. However, all cats managed to eat all of their food within $4 \mathrm{hr}$ after the initial starting time. With W/D dry diet, all cats ate $\geq 50 \%$ of their food within $30 \mathrm{~min}$. However, 2 cats managed to eat all of their food within $4 \mathrm{hr}$, while the remaining 3 cats required $8 \mathrm{hr}$ after the starting time, respectively, to finish all of their food. With M/D dry diet, three cats ate all of their food, whereas 2 cats were able to consume $\geq 50 \%$ of their food within $30 \mathrm{~min}$, respectively. The remaining 2 cats required up to $4 \mathrm{hr}$ after the starting time to finish all of their food. Lastly, with C/D dry diet, 4 cats managed to eat all of their food within $30 \mathrm{~min}$. The last cat ate $\geq 50 \%$ of its food within $30 \mathrm{~min}$, requiring up to $4 \mathrm{hr}$ after the starting time to completely finish all of its food.

Effect of prescription diets on postprandial serum glucose concentration inobese cats:Temporal analysis of postprandial glucose concentrations with each type of diet indicated no significant differences over time with any of the diets (Fig. 2a). However, significant differences were observed in mean $( \pm \mathrm{SD})$ glucose AUC between the 4 diets $(P<0.010$, one-way repeated measures ANOVA). The $\mathrm{M} / \mathrm{D}$ and Diabetic dry diets resulted in significantly lower glucose AUCs (821.2 \pm 94.4 and $804.8 \pm 129.2 \mathrm{mg} / \mathrm{d} l \cdot \mathrm{hr}^{-1}$, respectively) than that of the $\mathrm{C} / \mathrm{D}$ diet $\left(921.2 \pm 161.4 \mathrm{mg} / \mathrm{d} l \mathrm{hr}^{-1}\right)$. The glucose AUC of the W/D diet $\left(879.5 \pm 134.2 \mathrm{mg} / \mathrm{d} l \cdot \mathrm{hr}^{-1}\right)$ was slightly lower than that of the $\mathrm{C} / \mathrm{D}$ diet, but the difference was not regarded as being significant. In addition, significant differences were observed in mean peak concentrations of glucose between 

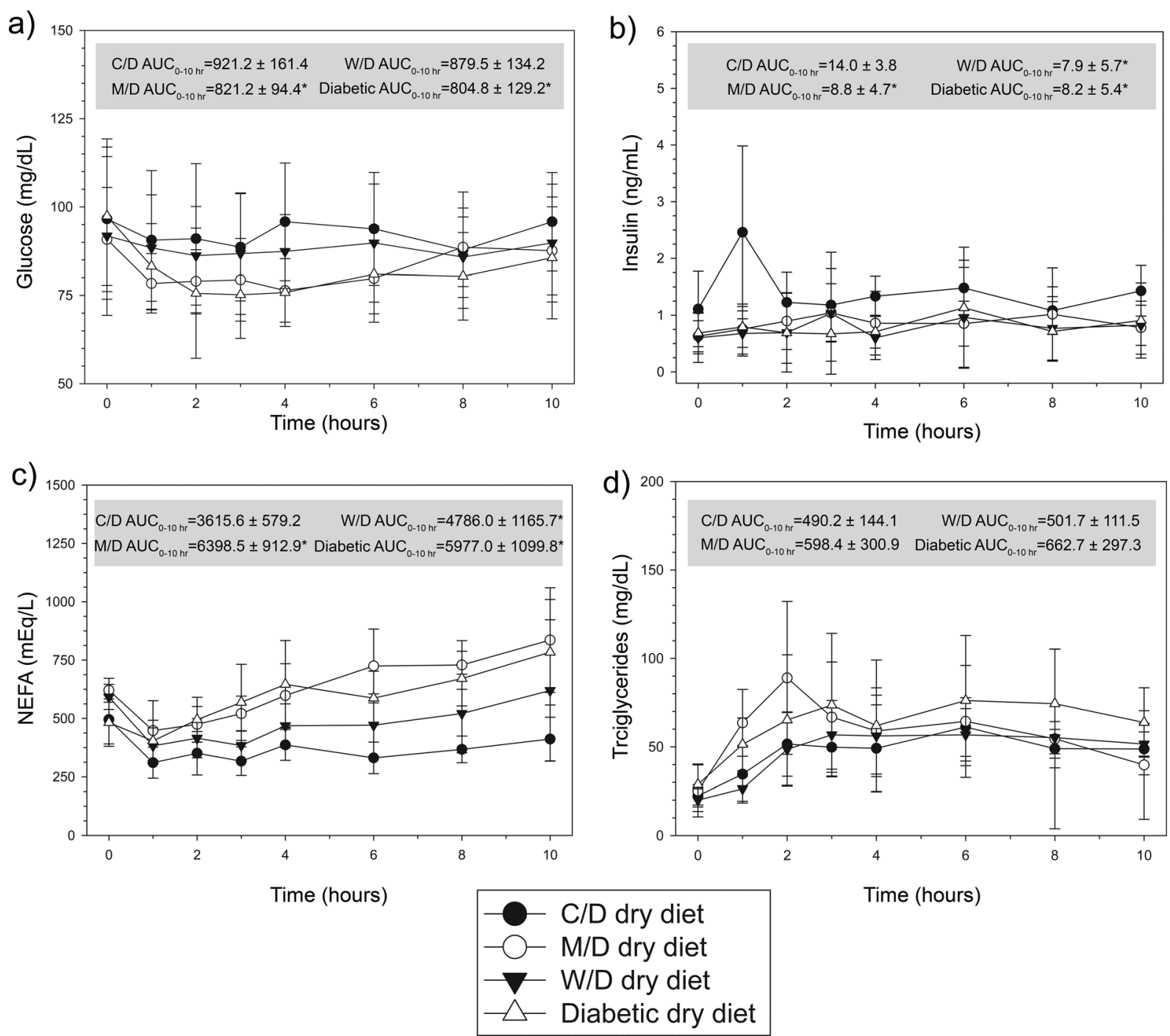

Fig. 2. Mean temporal changes in postprandial serum (a) glucose, (b) insulin, (c) nonesterified fatty acid (NEFA) and (d) triglycerides (TG) concentrations under different diet regimens in obese cats $(n=5)$. Results are expressed as means \pm SD. Total area under the curve (AUC) results are presented in the insets within the graphs. Asterisks indicate significance $(P<0.05$; Bonferroni's multiple comparison test) when compared with the $\mathrm{C} / \mathrm{D}$ diet.

Table 2. Comparison of peak metabolite concentrations with different diet regimens

\begin{tabular}{|c|c|c|c|c|c|c|c|c|}
\hline \multirow[t]{2}{*}{$\begin{array}{c}\text { Diet } \\
\text { Regimen }\end{array}$} & \multicolumn{2}{|c|}{$\begin{array}{l}\text { Glucose } \\
(\mathrm{mg} / \mathrm{d} /)\end{array}$} & \multicolumn{2}{|c|}{$\begin{array}{l}\text { Insulin } \\
(\mathrm{ng} / \mathrm{m} l)\end{array}$} & \multicolumn{2}{|c|}{$\begin{array}{c}\mathrm{TG} \\
(\mathrm{mg} / \mathrm{d} l)\end{array}$} & \multicolumn{2}{|c|}{$\begin{array}{c}\text { NEFA } \\
(\mathrm{mEq} / \mathrm{L})\end{array}$} \\
\hline & Mean & SD & Mean & SD & Mean & SD & Mean & SD \\
\hline $\mathrm{C} / \mathrm{D}$ dry & 99.2 & 16.8 & 2.7 & 1.2 & 63.6 & 16.9 & 441.6 & 88.5 \\
\hline M/D dry & 90.4 & 11.8 & 1.3 & 0.8 & 94.8 & 39.5 & 869.2 & $196.4 *$ \\
\hline W/D dry & 96.0 & 14.0 & 1.2 & 0.9 & 69.0 & 17.0 & 626.2 & 296.0 \\
\hline Diabetic dry & 87.8 & $16.6^{*}$ & 1.3 & 1.0 & 86.0 & 32.0 & 823.6 & $231.6^{*}$ \\
\hline
\end{tabular}

Asterisks indicate significant differences when compared with the C/D diet $(P<0.05$, Bonferroni's one-way ANOVA multiple comparison test). 
Table 3. Comparison of time to peak metabolite concentrations with different diet regimens

\begin{tabular}{|c|c|c|c|c|c|c|c|c|}
\hline \multirow[t]{2}{*}{$\begin{array}{c}\text { Diet } \\
\text { Regimen }\end{array}$} & \multicolumn{2}{|c|}{$\begin{array}{l}\text { Glucose } \\
\text { Time (hr) }\end{array}$} & \multicolumn{2}{|c|}{$\begin{array}{c}\text { Insulin } \\
\text { Time (hr) }\end{array}$} & \multicolumn{2}{|c|}{$\begin{array}{c}\text { TG } \\
\text { Time (hr) }\end{array}$} & \multicolumn{2}{|c|}{$\begin{array}{c}\text { NEFA } \\
\text { Time (hr) }\end{array}$} \\
\hline & Mean & SD & Mean & SD & Mean & SD & Mean & SD \\
\hline $\mathrm{C} / \mathrm{D}$ dry & 5.0 & 3.1 & 2.6 & 2.3 & 4.8 & 1.7 & 5.8 & 3.8 \\
\hline $\mathrm{M} / \mathrm{D}$ dry & 8.8 & 1.0 & 6.2 & 2 & 1.8 & $0.8^{*}$ & 8.8 & 1.7 \\
\hline W/D dry & 7.2 & 3.0 & 5.4 & 4.2 & 5.6 & 1.6 & 8.4 & 2.6 \\
\hline Diabetic dry & 6.4 & 4.9 & 3.6 & 2.5 & 5.0 & 2.5 & 8.8 & 2.6 \\
\hline
\end{tabular}

Asterisk indicates significant differences when compared with the $\mathrm{C} / \mathrm{D}$ diet $(P<0.05$, Bonferroni's one-way ANOVA multiple comparison test).

the 4 diets (one-way repeated measures ANOVA). When compared amongst the various diets, the $\mathrm{C} / \mathrm{D}$ diet resulted in a significantly higher peak concentration of glucose $(99 \pm 17$ $\mathrm{mg} / \mathrm{d} l)$ than the diabetic diet $(87 \pm 17 \mathrm{mg} / \mathrm{d} l)$ (Table 2). There were no significant differences in time to peak of glucose between the 4 diets (Table 3).

Effect of prescription diets on postprandial serum insulin concentration in obese cats: Temporal analysis of postprandial serum insulin concentrations, with each type of diet, indicated no significant difference in insulin sensitivity over time; however, the $\mathrm{C} / \mathrm{D}$ diet tended to result in the greatest insulin concentration amongst all of the diets (Fig. 2b). A significant difference was observed in mean $( \pm \mathrm{SD})$ insulin AUC between the 4 diets ( $P=0.004$, one-way repeated measures ANOVA). The M/D, W/D and Diabetic diets ( $8.8 \pm 4.7$, $7.9 \pm 5.7$ and $8.2 \pm 5.4 \mathrm{ng} / \mathrm{ml} \cdot \mathrm{hr}^{-1}$, respectively) all resulted in a significantly lower insulin AUC than the C/D diet (14.0 $\left.\pm 3.8 \mathrm{ng} / \mathrm{ml} \cdot \mathrm{hr}^{-1}\right)$. A significant difference was also observed in mean $( \pm \mathrm{SD})$ peak concentrations of insulin between all four diets $(P<0.05$, one-way repeated measures ANOVA) (Table 2); however, no significant difference in time to peak of insulin was observed between the diets (Table 3 ).

Effect of prescription diets on postprandial serum TG concentration in obese cats: Temporal analysis of postprandial serum TG concentrations indicated no significant differences in TG concentrations over time between each type of diet (Fig. 2c). Furthermore, no significant difference was observed in mean $( \pm$ SD) TG AUC between any of the 4 diets $(P=0.311$, one-way repeated measures ANOVA). In addition, no significant differences in peak concentrations of TG were observed between the 4 diets (Table 2). However, a significant difference was observed in mean $( \pm \mathrm{SD})$ time to peak of TG between the four diets $(P<0.05,1$-way repeated measures ANOVA) (Table 3$)$. When comparing the different diets, the $\mathrm{M} / \mathrm{D}$ diet $(1.8 \pm 0.8 \mathrm{hr})$ resulted in a significantly shorter time to peak than the W/D diet (5.6 $\pm 1.6 \mathrm{hr}$ ) (Table 3$)$.

Effect of prescription diets on postprandial serum NEFA concentration in obese cats: Temporal analysis of postprandial serum NEFA concentrations indicated significant differences over time between diets $(P<0.05,2$-way repeated measures ANOVA) (Fig. 2d). A significant difference was observed in mean ( \pm SD) NEFA AUC between the 4 diets $(P<0.001,1$-way repeated measures ANOVA). The M/D and Diabetic diets $(6,398.5 \pm 912.9$ and 5,977.0 $\pm 1,099.8$ $\mathrm{mEq} / \mathrm{L} \cdot \mathrm{hr}^{-1}$, respectively) resulted in a significantly higher
NEFA AUCs than the C/D diet $(3615.6 \pm 579.2 \mathrm{mEq} / \mathrm{L}$. $\left.\mathrm{hr}^{-1}\right)$. Although the W/D diet NEFA AUC (4,786.0 $\pm 1,165.7$ $\mathrm{mEq} / \mathrm{L} \cdot \mathrm{hr}^{-1}$ ) was slightly higher than that of the C/D diet, the increase was not deemed to be significant. In addition, significant differences were observed in mean $( \pm$ SD) peak concentrations of NEFA between the diets $(P<0.05,1$-way repeated measures ANOVA). The $\mathrm{C} / \mathrm{D}$ diet resulted in a significantly lower peak concentration of NEFA $(441 \pm 88$ $\mathrm{mEq} / \mathrm{L})$ than either the M/D $(869 \pm 196 \mathrm{mEq} / \mathrm{L})$ or Diabetic $(823 \pm 231 \mathrm{mEq} / \mathrm{L})$ diet (Table 2). Lastly, no significant difference in time to peak of NEFA was observed between the four diets (Table 3 ).

\section{DISCUSSION}

Given that postprandial serum glucose and insulin concentrations in obese cats can be drastically changed and altered by diet, as compared with healthy cats $[8,26]$, we assessed and compared the influence of four different commercially available prescription feline diets on in terms of postprandial glucose, insulin, triglyceride (TG) and nonesterified fatty acid (NEFA) concentrations, four important key parameters often monitored and assessed in obese and diabetic cats. There are currently a large number of diets available commercially for cats, which vary greatly in nutrient composition. Most diets are comprised of 4 major macronutrient categories: carbohydrates, protein, fiber and fat, with a selection of various micronutrients. There has been much research as to what degree each macronutrient category may influence or contribute to blood metabolite concentrations.

In fact, in spite of the fact that cats are strict carnivores and do not metabolize carbohydrates efficiently, most commercially available dry cat foods are moderate to high in carbohydrate content ( $>25-55 \%$ metabolizable energy (ME)), partly because of 1) the difficulty in formulating extruded, dry diets that are low in carbohydrates, and 2) because cereal is a relatively inexpensive ingredient, and there is demand for lower-cost diets in the pet food market. The typical prey diet of cats is low in carbohydrates $(<10 \% \mathrm{ME})$ [36].

Overall, we demonstrated that a low-carbohydrate, highprotein diet (M/D and Diabetic diets used in this study) can significantly lower postprandial glucose AUC greater than the $\mathrm{C} / \mathrm{D}$ and $\mathrm{W} / \mathrm{D}$ diets, which have higher carbohydrate contents. Our results corroborate a previous study reporting that healthy cats fed a diet for 4 weeks with approximately 
$50 \%$ of energy from carbohydrates, demonstrated a significantly higher mean glucose concentration and glucose AUC as compared with cats fed diets with $25 \%$ of energy from carbohydrates [11]. Interestingly, the $\mathrm{M} / \mathrm{D}$ and Diabetic diets also resulted in a postprandial glucose level lower than the preprandial level, in which is consistent with our results from a previous study where healthy cats were used [28].

In fact, differences in glucose concentration after consuming diets with differing starch levels has been observed between cats and dogs. Although a high starch diet increases plasma glucose concentrations in both animal species, a markedly prolonged elevation of plasma glucose concentration is present in cats $[16,17]$. Hewson-Hughes et al. [16, 17] previously demonstrated that as compared with dogs, cats have a slower, delayed and lower rate of insulin secretion when eating a meal with added glucose. Recent theories suggest that high-carbohydrate diets may lead to DM in felines, since carnivores are not well adapted to readily metabolize large amounts of glucose efficiently, as a source of energy [20]. Moreover, cats lack salivary amylase and demonstrate low activity of intestinal enzymes commonly involved in carbohydrate breakdown, such as intestinal amylase and disaccharidases [8].

Interestingly though, although both the Diabetic and M/D diets resulted in similar and comparable postprandial glucose AUC values, the M/D diet resulted in a significantly lower peak concentration of glucose versus the $\mathrm{C} / \mathrm{D}$ diet while containing twice as much carbohydrate content as compared with the M/D diet (6.7 vs $3.7 \mathrm{~g} / 100 \mathrm{kcal}$ of dry food). This observation may be attributed to the fact that 1 ) the M/D diet also has twice the fiber content of the Diabetic diet (3.1 vs $1.3 \mathrm{~g} / 100 \mathrm{kcal}$ of dry food) and 2) both diets have varying types of fiber, with the content of fiber in the M/D diet being mainly cellulose (insoluble fiber), whereas the Diabetic diet contained a mix of cellulose and beet pulp (soluble and insoluble fiber). Reducing the energy density of food by decreasing fat content and increasing fiber concentration is a strategy widely used for the management of obesity in pet animals [39]. The main rationale is that these diets provide a greater satiety stimulus, because a larger volume of food is ingested [36]. Fiber is a significant ingredient that can lower postprandial glucose responses, thereby also lowering postprandial insulin secretion in the process $[15,41]$. Furthermore, insoluble fiber, the type of fiber present in commercial feline high-fiber diets, has been shown to improve glycemic control in diabetic cats [32]. Based on human medical studies, fiber appears to slow intestinal carbohydrate absorption by: 1) slowing gastrointestinal transit times and gastric emptying and 2) decreasing starch hydrolysis and, consequently, the rate of glucose absorption [2, 9]. Consequently, use of high fiber foods for glycemic control in diabetic cats has also been suggested.

It is currently debatable as to whether or not a high-protein diet increases postprandial insulin in humans and rats [7, 14, 34, 38]. High-protein, low-carbohydrate diets reduce postprandial hyperglycemia, but also decrease the overall insulin requirement, possibly indicating a reduced demand on the $\beta$-cells to produce insulin in diabetic cats [5]. A low- carbohydrate diet may aid in glycemic control in diabetic cats by decreasing hyperglycemia and markedly decrease the in insulin dose $[13,27]$. Postprandial insulin secretion was observed in all four prescription diets. However, apparent insulin secretion was only observed in the C/D diet group after $1 \mathrm{hr}$ post feeding. Furthermore, the preprandial insulin level with the $\mathrm{C} / \mathrm{D}$ diet was higher than with the other three diabetic prescription diets, and was maintained at higher levels, for up to $10 \mathrm{hr}$ post feeding. Thus, all three diabetic prescription diets may also be able to moderate postprandial insulin secretion. Moreover, all 3 DM-targeted diets (M/D, W/D and Diabetic diets) had higher protein amounts than the $\mathrm{C} / \mathrm{D}$ diet, which did not increase postprandial serum insulin concentrations in the present study. However, of the 3 diabetic prescription diets, the $\mathrm{M} / \mathrm{D}$ diet had the highest insulin AUC levels. One possible explanation is that the M/D diet contains rich amounts of arginine, which is a strong stimulus for invoking an insulin response in cats [22]. The M/D diet also contains the lowest amount of carbohydrates but highest amount of fat amongst the $3 \mathrm{DM}$ diets.

Dietary fat content may also affect the postprandial glucose concentration. Martin et al. [26] reported that mean postprandial glycemia increases from the use of high-fat diets as compared with high-protein diets. However, no significant difference in mean postprandial insulin concentration was observed between high-fat and high-protein diets. The authors speculated that fatty acid may be used as a substitute for glucose to supply energy in high-fat diets. However, another study demonstrated that plasma concentrations of insulin in cats given the highest-fat diet were greater than those of cats given lower-fat diets [4]. The M/D dry diet (highest fat content in the present study) did not induce postprandial hyperglycemia or any apparent insulin secretion, leading us to speculate that dietary fat content has less impact and effect on postprandial glucose and insulin concentration, as compared with dietary carbohydrate and fiber content in the present study.

Some micronutrients may have an influence on glucose and insulin metabolism. Chromium has been shown to reduce the glucose concentration and improve glucose tolerance in normal-weight cats [3]. In addition, intravenous calcium-stimulation tests resulted in a significant increase in plasma insulin concentration, but had no effect on plasma glucose concentrations [35]. Few studies have examined and elucidated the relationship between micronutrients and postprandial blood parameters, indicating that there is further need for futures studies in this area.

Obesity is associated with increased serum concentrations of triglycerides (TG) in cats. TGs play an important role in metabolism as energy sources and transporters of dietary fat. Because diets containing different amounts of fat (M/D high fat, $\mathrm{C} / \mathrm{D}$ - moderate fat, and W/D and Diabetic - low fat), we expected the postprandial TG concentrations to be affected by dietary fat amount. However, in the present study, postprandial serum TG concentrations did not differ between any of the prescription diets, leading us to speculate that changes in dietary fat amount do not affect postprandial TG concentrations on a short-term basis (1 week). 
In a human study, dietary fat was generally considered to reduce postprandial blood glucose and insulin concentrations because of reduced upper gastrointestinal motility [40]. However, a large part of the postprandial glucose and insulin responses was explained by the amount of carbohydrates in the meal [43]. In another study, differences in fat amount did not appear to affect postprandial glucose or insulin levels [33]; therefore, fat amounts can be readily altered without any negative outcome. In fact, dietary fat is reputed to enhance the palatability of diets made for cats, and this may be the sole reason for including it as a constituent [19]. However, a high-fat diet has been shown to induce insulin resistance, which can lead to increased insulin levels and DM eventually [23]. Therefore, further testing of diets with varying amounts of fat on a long-term basis should reveal more information about the relationship between postprandial serum TG concentration and insulin resistance in obese cats.

No significant changes were observed in time to peak concentrations of glucose, insulin and NEFA; however, TG with the M/D diet peaked significantly earlier than with the W/D diet. Since the fat content in the M/D diet was 1.9fold higher than that in the W/D diet, the higher fat content might have induced an earlier increase in TG concentration as compared with the W/D diet.

Postprandial serum NEFA concentrations differed between the 4 prescription diets. Fatty acids released from adipocytes are usually produced by the hydrolysis of TGs. Fat storage and accumulation in skeletal muscle and adipose tissues are regulated by 2 lipases, LPL (lipoprotein lipase) and HSL (hormone-sensitive lipase). Lipid storage in skeletal muscle and adipose tissues is entirely dependent on uptake of NEFAs released from the hydrolysis of circulating TG-rich lipoproteins by LPL [10]. Meanwhile, HSL is a ratelimiting enzyme involved in the hydrolysis of intracellular TGs to supply plasma NEFAs. In normal human subjects, the rise in plasma insulin after an oral glucose load rapidly suppresses plasma NEFAs. Insulin activates LPL in adipocytes; therefore, the serum NEFA concentration decreased after feeding with all of the diets. However, the serum NEFA concentration gradually increased thereafter with all the diets except for the $\mathrm{C} / \mathrm{D}$ diet.

In particular, the NEFA AUCs and peak concentrations with the M/D and Diabetic diets were significantly higher than those of the C/D diet. Our results corroborate those of a human study demonstrating significantly lower postprandial plasma NEFA using high-carbohydrate diets as opposed to low-carbohydrate diets [42]. HSL is activated when the body needs to mobilize energy stores and therefore responds positively to catecholamines and ACTH (adrenocorticotropic hormone) and negatively to insulin. The M/D and diabetic diets contain low amounts of carbohydrates, thereby reducing postprandial glucose concentrations, which might induce the secretion of catecholamines and ACTH. Therefore, it may be possible that the increase in postprandial serum NEFA concentration induced by the M/D and Diabetic diets leads to the conversion of fat into energy, thereby enhancing weight loss, which would be beneficial for obese cats feed- ing on either of these diets.

This study has a number of limitations. First, our results have low statistical power, which is attributed to the small number of obese cats. Therefore, due to the large biological variability amongst animals, the sample number used in our study is too small to accurately assess postprandial serum metabolites (e.g., glucose, insulin, TG and NEFA concentration) reliably. Second, the animals used in our study were not randomized, and therefore, our study was not blinded. Lastly, although a feline-specific insulin ELISA kit was used in our study, a large standard deviation was observed. Since this commercial kit was previously assessed for reproducibility [29], we consider any large standard deviation to be explained by the small number of obese cats $(n=5)$ and large variability between these individuals and not to be due to any limitation of the kit itself.

In conclusion, this study demonstrates that different prescription diets can significantly affect postprandial changes in the glucose and insulin responses of obese cats, thereby providing useful information for managing and treating diabetic cats. Overall, the M/D, W/D and Diabetic diets are aimed at weight management and treating DM, as described by their manufacturers. These diets are rich in fiber $(1.3,2.2$ and $3.1 \mathrm{~g} / 100 \mathrm{kcal}$, respectively), which can lower postprandial glucose levels and thereby lower postprandial insulin levels. Our results confirm that the M/D, W/D and Diabetic diets might be beneficial for cats with a combination of risk factors for diabetes, such as age, obesity and gender (e.g., male sex), as shown by the reduced incremental increase in postprandial serum glucose and insulin concentrations as compared with cats fed the $C / D$ diet. Because the $M / D$, W/D and Diabetic diets contain a large amount of fiber as compared with the $\mathrm{C} / \mathrm{D}$ diet, the relationship between dietary fiber amounts and contents and postprandial glucose and insulin secretion should be further studied. In addition, few studies have examined and elucidated the relationship between micronutrients and postprandial blood parameters, indicating that there is further need for future studies in this area also.

Lastly, given that our study was conducted with obese cats, it is very difficult to extrapolate any of our findings to cats suffering from DM per se. Therefore, it would be clinically more relevant and important to repeat this study on a long-term basis in cats suffering from DM in order to confirm whether the results in this study are applicable.

ACKNOWLEDGMENT. This work was supported by JSPS KAKENHI Grant number 22580370.

\section{REFERENCES}

1. Accurso, A., Bernstein, R. K., Dahlqvist, A., Draznin, B., Feinman, R. D., Fine, E. J., Gleed, A., Jacobs, D. B., Larson, G., Lustig, R. H., Manninen, A. H., McFarlane, S. I., Morrison, K., Nielsen, J. V., Ravnskov, U., Roth, K. S., Silvestre, R., Sowers, J. R., Sundberg, R., Volek, J. S., Westman, E. C., Wood, R. J., Wortman, J. and Vernon, M. C. 2008. Dietary carbohydrate restriction in type 2 diabetes mellitus and metabolic syndrome: 
time for a critical appraisal. Nutr. Metab. 5: 9. [CrossRef]

2. Anderson, J. W. and Akanji, A. O. 1991. Dietary fiber-an overview. Diabetes Care 14: 1126-1131. [Medline] [CrossRef]

3. Appleton, D. J., Rand, J. S., Sunvold, G. D. and Priest, J. 2002. Dietary chromium tripicolinate supplementation reduces glucose concentrations and improves glucose tolerance in normal-weight cats. J. Feline Med. Surg. 4: 13-25. [Medline] [CrossRef]

4. Backus, R. C., Cave, N. J. and Keisler, D. H. 2007. Gonadectomy and high dietary fat but not high dietary carbohydrate induce gains in body weight and fat of domestic cats. Br. J. Nutr. 98: 641-650. [Medline] [CrossRef]

5. Bennett, N., Greco, D. S., Peterson, M. E., Kirk, C., Mathes, M. and Fettman, M. J. 2006. Comparison of a low carbohydratelow fiber diet and a moderate carbohydrate-high fiber diet in the management of feline diabetes mellitus. J. Feline Med. Surg. 8: 73-84. [Medline] [CrossRef]

6. Biourge, V., Nelson, R. W., Feldman, E. C., Willits, N. H., Morris, J. G. and Rogers, Q. R. 1997. Effect of weight gain and subsequent weight loss on glucose tolerance and insulin response in healthy cats. J. Vet. Intern. Med. 11: 86-91. [Medline] [CrossRef]

7. Blázquez, E. and Lopez Quijada, C. 1970. The effect of a highprotein dier on plasma diet on plasma glucose concentration, insulin, sensitivity and plasma insulin in rats. J. Endocrinol. 46: 445-451. [Medline] [CrossRef]

8. Coradini, M., Rand, J. S., Morton, J. M. and Rawlings, J. M. 2011. Effects of two commercially available feline diets on glucose and insulin concentrations, insulin sensitivity and energetic efficiency of weight gain. Br. J. Nutr. 106: S64-S77. [Medline] [CrossRef]

9. Costacou, T. and Mayer-Davis, E. J. 2003. Nutrition and prevention of type 2 diabetes. Annu. Rev. Nutr. 23: 147-170. [Medline] [CrossRef]

10. Eckel, R. H. 1989. Lipoprotein lipase. A multifunctional enzyme relevant to common metabolic diseases. N. Engl. J. Med. 320: 1060-1068. [Medline]

11. Farrow, H. A., Rand, J. S. and Sunvold, G. D. 2002. The effect of high protein, high fat or high carbohydrate diets on postprandial glucose and insulin concentrations in normal cats. Abstract No 133, Proceedings 20th ACVIM, 794.

12. Fettman, M. J., Stanton, C. A., Banks, L. L., Hamar, D. W., Johnson, D. E., Hegstad, R. L. and Johnston, S. 1997. Effects of neutering on bodyweight, metabolic rate and glucose tolerance of domestic cats. Res. Vet. Sci. 62: 131-136. [Medline] [CrossRef]

13. Frank, G., Anderson, W., Pazak, H., Hodgkins, H., Ballam, J. and Laflamme, D. 2001. Use of a high-protein food in the management of feline diabetes mellitus. Vet. Ther. 2: 238-246. [Medline]

14. Gannon, M. C., Nuttall, F. Q., Saeed, A., Jordan, K. and Hoover, H. 2003. An increase in dietary protein improves the blood glucose response in persons with type 2 diabetes. Am. J. Clin. Nutr. 78: 734-741. [Medline]

15. Graham, P. A., Maskell, I. E. and Nash, A. S. 1994. Canned high fiber diet and postprandial glycemia in dogs with naturally occurring diabetes mellitus. J. Nutr. 124: 2712S-2715S. [Medline]

16. Hewson-Hughes, A. K., Gilham, M. S., Upton, S., Colyer, A., Butterwick, R. and Miller, A. T. 2011. Postprandial glucose and insulin profiles following a glucose-loaded meal in cats and dogs. Br. J. Nutr. 106:(Suppl. 1): S101-S104. [Medline] [CrossRef]

17. Hewson-Hughes, A. K., Gilham, M. S., Upton, S., Colyer, A., Butterwick, R. and Miller, A. T. 2011. The effect of dietary starch level on postprandial glucose and insulin concentrations in cats and dogs. Br. J. Nutr. 106:(Suppl. 1): S105-S109. [Medline] [CrossRef]

18. Ihle, S. L. 1995. Nutrtional therapy for diabetes mellitus. Vet. Clin. North. Am. Small Anim. Pract. 25: 585-597. [Medline]

19. Kane, E., Morris, J. G. and Rogers, Q. R. 1981. Acceptability and digestibility by adult cats of diets made with various sources and levels of fat. J. Anim. Sci. 53: 1516-1523. [Medline]

20. Kienzle, E. 1994. Blood sugar levels and renal sugar excretion after the intake of high carbohydrate diets in cats. J. Nutr. 124: 2563S-2567S. [Medline]

21. Kirk, C. A., Feldman, E. C. and Nelson, R. W. 1993. Diagnosis of naturally acquired type- I and type-II diabetes mellitus in cats. Am. J. Vet. Res. 54: 463-467. [Medline]

22. Kitamura, T., Yasuda, J. and Hashimoto, A. 1999. Acute insulin response to intravenous arginine in nonobese healthy cats. $J$. Vet. Intern. Med. 13: 549-556. [Medline] [CrossRef]

23. Li, L., Yang, G., Li, Q., Tang, Y. and Li, K. 2006. High-fat- and lipid-induced insulin resistance in rats: the comparison of glucose metabolism, plasma resistin and adiponectin levels. Ann. Nutr. Metab. 50: 499-505. [Medline] [CrossRef]

24. Link, K. R. and Rand, J. S. 1998. Reference values for glucose tolerance and glucose tolerance status in cats. J. Am. Vet. Med. Assoc. 213: 492-496. [Medline]

25. Lutz, T. A. and Rand, J. S. 1995. Pathogenesis of feline diabetes mellitus. Vet. Clin. North. Am. Small Anim. Pract. 25: 527-552. [Medline]

26. Martin, L. J., Siliart, B., Lutz, T. A., Biourge, V., Nguyen, P. and Dumon, H. J. 2010. Postprandial response of plasma insulin, amylin and acylated ghrelin to various test meals in lean and obese cats. Br. J. Nutr. 103: 1610-1619. [Medline] [CrossRef]

27. Mazzaferro, E. M., Greco, D. S., Turner, A. S. and Fettman, M. J. 2003. Treatment of feline diabetes mellitus using an alphaglucosidase inhibitor and a low-carbohydrate diet. J. Feline Med. Surg. 5: 183-189. [Medline] [CrossRef]

28. Mori, A., Sako, T., Lee, P., Nishimaki, Y., Fukuta, H., Mizutani, H., Honjo, T. and Arai, T. 2009. Comparison of three commercially available prescription diet regimens onshort-term postprandial serum glucose and insulin concentrations in healthy cats. Vet. Res. Commun. 33: 669-680. [Medline] [CrossRef]

29. Nakaya, M., Kito, Y., Matsuki, N., Shibata, H., Touhata, Y., Tamahara, S. and Ono, K. 2009. A novel sandwich enzyme-linked immunosorbent assay for feline insulin. J. Vet. Med. Sci. 71: 1005-1007. [Medline] [CrossRef]

30. Nelson, R. W. 1992. Dietary management of diabetes mellitus. $J$. Small. Anim. Pract. 33: 213-217. [CrossRef]

31. Nelson, R. W., Himsel, C. A., Feldman, E. C. and Bottoms, G. D. 1990. Glucose tolerance and insulin response in normal-weight and obese cats. Am. J. Vet. Res. 51: 1357-1362. [Medline]

32. Nelson, R. W., Scott-Moncrief, J. C., Feldman, E. C., DeVriesConcannon, S. E., Kass, P. H., Davenport, D. J., Kiernan, C. T. and Neal, L. A. 2000. Effect of dietary insoluble fiber on control of glycemia with naturally acquired diabetes mellitus. J. Am. Vet. Med. Assoc. 216: 1082-1088. [Medline] [CrossRef]

33. Robertson, M. D., Henderson, R. A., Vist, G. E. and Rumsey, R. D. E. 2002. Extended effects of evening meal carbohydrate-tofat ratio on fasting and postprandial substrate metabolism. Am. J. Clin. Nutr. 75: 505-510. [Medline]

34. Sargrad, K. R., Homko, C., Mozzoli, M., Boden, G. and Perry, M. L. 2005. Effect of high protein vs high carbohydrate intake on insulin sensitivity, body weight, hemoglobin Alc, and blood pressure in patients with type 2 diabetes mellitus. J. Am. Diet Assoc. 105: 573-580. [Medline] [CrossRef] 
35. Slingerland, L. I., Rijnberk, A. and Kooistra, H. S. 2008. Calcium-stimulation test for the assessment of beta-cell function in cats. Res. Vet. Sci. 84: 364-366. [Medline] [CrossRef]

36. Thatcher, C. D., Hand, M. S. and Remillard, R. L. 2010. Small animal clinical nutrition: an iterative process. In: Small Animal Clinical Nutrition, 5th ed. (Hand, M. S., Thatcher, C. D., Remillard, R. L., Roudebush, P. and Novotnu, B. J. eds.). Walsworth Publishing Co., Marceline, Missouri.

37. Thiess, S., Becskei, C., Tomsa, K., Lutz, T. A. and Wanner, M. 2004. Effects of high carbohydrate and high fat diet on plasma metabolite levels and on i.v. glucose tolerance test in intact and neutered male cats. J. Feline Med. Surg. 6: 207-218. [Medline] [CrossRef]

38. Usami, M., Seino, Y., Seino, S., Takemura, J., Nakahara, H., Ikeda, M. and Imura, H. 1982. Effects of high protein diet on insulin and glucagon secretion in normal rats. J. Nutr. 112: 681-685. [Medline]

39. Vasconcellos, R. S., Borges, N. C., Gonçalves, K. N., Canola, J. C., de Paula, F. J., Malheiros, E. B., Brunetto, M. A. and Car- ciofi, A. C. 2009. Protein intake during weight loss influences the energy required for weight loss and maintenance in cats. $J$. Nutr. 139: 855-860. [Medline] [CrossRef]

40. Welch, I. M., Bruce, C., Hill, S. E. and Read, N. W. 1987. Duodenal and ileal lipid suppresses postprandial blood glucose and insulin responses in man: possible implications for the dietary management of diabetes mellitus. Clin. Sci. 72: 209-216. [Medline]

41. Wolever, T. M. 1990. Relationship between dietary fiber content and composition in foods and the glycemic index. Am. J. Clin. Nutr. 51: 72-75. [Medline]

42. Wolever, T. M., Bentum-Williams, A. and Jenkins, D. J. 1995. Physiological modulation of plasma free fatty acid concentrations by diet. Metabolic implications in nondiabetic subjects. Diabetes Care 18: 962-970. [Medline] [CrossRef]

43. Wolever, T. M. and Bolognesi, C. 1996. Source and amount of carbohydrate affect postprandial glucose and insulin in normal subjects. J. Nutr. 126: 2798-2806. [Medline] 